\title{
O Programa Minha Casa Minha Vida nas regiões metropolitanas de São Paulo e Campinas: aspectos socioespaciais e segregação
}

\author{
The Program Minha Casa Minha Vida \\ in the metropolitan regions of São Paulo \\ and Campinas: socio-spatial aspects and segregation
}

Raquel Rolnik et al.

\begin{abstract}
Resumo
Lançado em 2009, o Programa Minha Casa Minha Vida (PMCMV), atual política habitacional do Governo Federal, vem desencadeando impactos territoriais significativos nas cidades brasileiras. Embora o programa tenha alçado o tema da habitação a uma posição de destaque na agenda do Governo Federal, incluindo grandes subsídios, o padrão de inserção urbana de seus empreendimentos reafirma a predominância de um modelo de urbanização excludente e precário na maior parte das cidades do país, especialmente nas principais regiões metropolitanas. É o que o artigo procura demonstrar, a partir de uma análise dos padrões de inserção urbana dos empreendimentos produzidos no âmbito do PMCMV, entre 2009 e 2012, nas regiões metropolitanas de São Paulo e Campinas.

Palavras-chave: política habitacional; Minha Casa Minha Vida; inserção urbana; segregação urbana.
\end{abstract}

\begin{abstract}
Launched in 2009, the Program Minha Casa Minha Vida (PMCMV - My House My Life), the current housing policy of the Federal Government, has promoted significant territorial impacts on Brazilian cities. Although the program has increased the importance of the housing issue within the Federal Government's agenda, including large amounts of subsidies, the urban integration pattern of its enterprises reaffirms the predominance of an exclusionary and precarious urbanization model in most cities of the country, especially in the main metropolitan areas. This is what this article aims to demonstrate, based on an analysis of the urban integration patterns of the enterprises produced under the PMCMV between 2009 and 2012 in the metropolitan regions of São Paulo and Campinas.
\end{abstract}

Keywords: housing policy; Minha Casa Minha Vida; urban integration; urban segregation. 


\section{Introdução}

Este artigo apresenta resultados preliminares da pesquisa "Ferramentas para avaliação da inserção urbana dos empreendimentos do Programa Minha Casa Minha Vida (PMCMV)" desenvolvida pelo Laboratório Direito à Cidade e Espaço Público da Faculdade de Arquitetura e Urbanismo da Universidade de São Paulo (LabCidade - FAU/USP). A pesquisa insere-se num projeto coletivo desenvolvido pela Rede Cidade e Moradia. ${ }^{1} 0$ artigo analisa o padrão de inserção urbana dos conjuntos habitacionais que foram produzidos no âmbito do PMCMV nas regiões metropolitanas de São Paulo e de Campinas até $2012,{ }^{2}$ trazendo uma reflexão sobre seus impactos nas respectivas configurações territoriais e padrões de segregação socioespacial. ${ }^{3}$ Para isso, serão apresentadas: (1) explicações sobre o funcionamento do programa em suas diferentes modalidades; (2) uma breve caracterização da estrutura das regiões metropolitanas abordadas; e (3) análises da relação entre a inserção dos conjuntos e os padrões de segregação socioespacial vigentes nos respectivos territórios.

Nossa hipótese é a de que, embora seja inovador na concessão de um volume significativo de subsídios para o atendimento das necessidades habitacionais dos setores de renda mais baixa da população e na ampliação e barateamento do crédito para a compra de imóveis por setores de renda intermediária, o programa não levou em conta a dimensão territorial como um aspecto relevante de uma política habitacional orientada para a universalização do acesso à moradia em condições adequadas, tendo negligenciado o enfrentamento do problema da segregação socioespacial em função da renda nas cidades brasileiras. Pelo contrário, verificou-se que a sistemática do programa, atribuindo um protagonismo na concepção das operações às construtoras privadas, que geralmente se incumbem da elaboração de projetos e da escolha de terrenos, incentivou a proliferação de grandes conjuntos em lugares onde o custo da terra é o mais baixo possível - uma condição fundamental para a rentabilidade das operações -, reiterando um padrão histórico de ocupação do território onde o assentamento da população pobre é feito prioritariamente em periferias precárias e mal equipadas.

Embora tenha-se constatado que o PMCMV venha exercendo um papel ativo na reprodução da segregação em função da renda e na reafirmação da periferia como lugar dos pobres nas cidades brasileiras, identificaram-se mudanças importantes no que é essa periferia e no papel desempenhado pelas políticas públicas de habitação em sua expansão nos dias de hoje. A periferia das cidades estudadas passou por um processo de urbanização cumulativo, o que atenuou sua precariedade em comparação com contextos anteriores. Além disso, essas cidades têm hoje uma estrutura mais multipolar do que tinham há décadas, 0 que altera as condições de inserção urbana de áreas que, embora ainda sejam periféricas, não estão sujeitos ao mesmo nível de isolamento de um passado não muito distante. Diferentemente do que ocorria em experiências anteriores como a do $\mathrm{BNH}$, os empreendimentos do PMCMV vêm sendo implantados em áreas periféricas, porém contíguas à malha urbana 
pré-existente, não exercendo a mesma pressão no sentido da abertura de novos focos de urbanização em áreas rurais. Embora o PMCMV reforce o padrão periférico da moradia dos segmentos de baixa renda, as desigualdades socioespaciais nas cidades de hoje e a expansão de suas periferias não são as mesmas das décadas de crescimento urbano explosivo da segunda metade do século $X X$.

Apesar das tendências gerais apontadas acima, constatou-se a predominância de padrões um pouco distintos nos empreendimentos das duas regiões metropolitanas estudadas. Na RMSP, identificou-se grande incidência de empreendimentos de pequeno e médio porte em interstícios de periferias razoavelmente consolidadas, sendo grande parte delas áreas remanescentes de antigos projetos produzidos por companhias habitacionais. Já em Campinas, constatou-se uma predominância de conjuntos de grande porte produzidos em terrenos privados nas bordas da mancha urbana. Essas características decorrem em parte da estrutura dessas duas regiões metropolitanas e em parte da ação de agentes locais, levando a impactos territoriais de intensidade bem diferentes. No entanto, a despeito dessas especificidades locais e da diferença do padrão periférico de hoje em relação a contextos anteriores, identificou-se o programa como um vetor de reprodução da segregação socioespacial nas cidades brasileiras, o que é uma consequência inevitável do modelo que orientou sua formulação, permeado por objetivos que vão além da promoção do direito à moradia.

\section{Sobre o Programa Minha Casa Minha Vida}

O PMCMV foi lançado em março de $2009^{4}$ pelo Governo Federal, tendo como principal finalidade anunciada contribuir para a redução do déficit habitacional no país por meio da concessão de incentivos à produção e compra de novas unidades habitacionais. Em sua primeira fase, compreendida entre março de 2009 e meados de 2011, estabeleceu-se como meta a construção de um milhão de novas moradias. Em sua segunda fase, iniciada em meados de 2011 e prevista para se extender até o final de 2014, dobrou-se a meta da primeira fase, prevendo-se a construção de mais dois milhões de unidades habitacionais.

0 programa foi formulado para atender a três faixas de renda distintas, com metas, mecanismos de contratação e subvenções econômicas diferentes. A Faixa 1 é destinada ao atendimento de famílias com renda mensal de até $\mathrm{R} \$ 1.600,00$; a Faixa 2 a famílias com renda mensal entre $R \$ 1.600,00$ e $R \$ 3.100,00$; e a Faixa 3 a famílias com renda entre $\mathrm{R} \$ 3.100,00$ e $R \$ 5.000,00 . .^{5}$ Na primeira fase do programa, estabeleceu-se como meta a construção de 400 mil U.H. para a Faixa 1; 400 mil U.H. para a Faixa 2; e 200 mil U.H. para a Faixa 3. Na segunda fase, as metas previstas foram de 1.2 milhão de U.H. para a Faixa 1; 600 mil U.H. para a Faixa 2; e 200 mil U.H. para a Faixa 3, dando-se maior prioridade ao atendimento das faixas de menor renda do que na etapa anterior. 
No caso dos empreendimentos da Faixa 1, a demanda é inteiramente indicada pelos governos locais. A construtora é remunerada pela execução do projeto diretamente pelo FAR, não se sujeitando ao risco de inadimplência dos beneficiários e não exercendo qualquer atribuição relacionada à comercialização dos imóveis. As famílias beneficiadas responsabilizam-se por efetuar pagamentos mensais ao longo de um período de dez anos. Os valores pagos pelos beneficiários correspondem a uma parcela muito pequena do custo individual das unidades, cuja produção é quase integralmente subsidiada pelo Fundo de Arrendamento Residencial (FAR), que recebe aportes do Orçamento Geral da União (OGU) para arcar com os custos do programa. ${ }^{6}$ Para essa faixa de renda há também a modalidade "Entidades", em que a construção do empreendimento é contratada junto a organizações representativas de movimentos de moradia. Nesse caso, as entidades responsabilizam-se pela construção do empreeendimento e pela indicação dos beneficiários. Nessa modalidade, o financiamento é feito pelo Fundo de Desenvolvimento Social (FDS).

As condições são bem diferentes no caso dos empreendimentos destinados à Faixa 2 e à Faixa 3, que integram o chamado "mercado popular". Nesses casos, a construtora figura como incorporadora da operação, responsabilizando-se pela comercialização das unidades. Os beneficiários celebram contratos de compra e venda diretamente com a construtora, recebendo financiamento para a compra das unidades. 0 financiamento é concedido pela CAIXA com recursos do Fundo de Garantia do Tempo de Serviço (FGTS). No caso da Faixa 2, os beneficiários contam com o abatimento de uma parte da entrada, o que caracteriza uma forma de subsídio direto não aplicável à Faixa 3. As faixas 2 e 3 contam com um seguro de crédito concedido pelo Fundo Garantidor da Habitação (FGHab), instituído juntamente com o programa. Embora as linhas de financiamento concedidas pela CAIXA no âmbito do programa disponham de condições mais favoráveis do que as de mercado e sejam garantidas por um fundo público, o que caracteriza subsídio indireto, a subvenção concedida a essas faixas é bem inferior à da Faixa 1, em que 0 valor arcado pelo beneficiário é praticamente simbólico. Assim, pode-se dizer que sob o nome "Minha Casa Minha Vida" abriga-se um conjunto diversificado de ações com lógicas e objetivos distintos.

Para além do enfrentamento das necessidades habitacionais, o lançamento do programa surgiu como medida emergencial para minimizar o impacto da crise internacional de 2008 sobre o emprego e o crescimento econômico no Brasil. O PMCMV foi concebido com o intuito de promover o aquecimento da economia por meio do estímulo ao setor da construção civil, segmento que gera demanda expressiva por mão de obra de baixa qualificação, sendo frequentemente mobilizado como elemento de políticas econômicas anticíclicas em momentos de recessão. Tendo em vista os objetivos macroeconômicos por trás de sua criação, para que o programa pudesse atender a todos os seus propósitos, viabilizar a produção de uma quantidade expressiva de novas moradias num curto espaço de tempo revelou-se uma exigência fundamental, o que exerceu influência determinante sobre o padrão de inserção urbana dos empreendimentos. A convergência de interesses de construtoras, governos locais e 0 Governo Federal em fazer o programa "rodar" 
suplantou preocupações com aspectos como a qualidade urbanística do entorno dos empreendimentos e a articulação da oferta habitacional com uma política fundiária abrangente, uma vez que considerações desse tipo afetariam a velocidade de sua implementação.

Além dos fatores macroeconômicos, outro aspecto não diretamente relacionado às necessidades habitacionais do país que influenciou o desenho do PMCMV foi uma conjuntura específica do setor imobiliário. Várias das principais empresas desse segmento haviam aberto seu capital na bolsa de valores nos anos anteriores à crise. Uma estratégia adotada para que pudessem captar investimentos foi a projeção de um alto valor geral de vendas (VGV) nos anos subsequentes. Para que pudessem ampliar suas carteiras de projetos, muitas dessas empresas formaram grandes bancos de terra. No entanto, com a mudança do cenário econômico e a consequente tendência de retração da disponibilidade de crédito para a produção e a compra de imóveis, essas empresas viram-se diante de uma situação bastante delicada, com perspectivas reais de quebra generalizada no setor. Tendo sido formulado com intensa participação de representantes dessas empresas, para além de uma política habitacional e de um pacote econômico de caráter anticíclico, o PMCMV foi também uma saída encontrada para evitar a falência generalizada de empresas de grande porte no setor imobiliário, mantendo a oferta de crédito no patamar necessário para que 0 setor pudesse manter suas atividades em ritmo acelerado e, assim, dar vazão ao capital imobilizado na formação de estoques de terra no período anterior. A produção destinada às faixas 2 e 3 foi particularmente importante para absorver o estoque fundiário dessas empresas.
0 modelo adotado inspirou-se em políticas habitacionais que já vinham sendo implementadas em outros países da América Latina, como México e Chile, desde os anos 1980. Em linhas gerais, essas experiências promoveram um modelo de inclusão pelo consumo, em que a moradia para a população de baixa renda deve ser ao mesmo tempo uma mercadoria a ser acessada por meio de relações de mercado e uma oportunidade de negócio para empresas privadas. Assim como no caso do PMCMV, essas políticas habitacionais tiveram como aspectos fundamentais a produção em grande escala por empresas privadas e a concessão de subsídios governamentais diretos ao comprador para viabilizar a compra da casa própria por grupos que estariam fora do mercado (Rodriguez e Sugranyes, 2005).

0 programa afastou-se de diretrizes urbanísticas constantes na política habitacional tal como formulada pelo Sistema Nacional de Habitação de Interesse Social (SNHIS), instituido pela Lei 11.124/2005, e pelo Plano Nacional de Habitação (PlanHab), lançado em 2009 (Bonduki, 2009). As normas que orientam sua implementação não foram pautadas pelas estratégias de enfrentamento do déficit habitacional contidas na política de habitação recém-elaborada (Krause, Balbim e Lima Neto, 2013), mas por uma agenda atrelada aos fatores macroeconômicos e setoriais mencionados.

0 desenho do programa é um fator determinante para a reprodução do padrão periférico da moradia da população de baixa renda no país. 0 protagonismo das construtoras na proposição de projetos e na seleção de terrenos relega a inserção urbana dos empreendimentos a uma questão de relevância secundária, senão inexistente. Embora alguns municípios 
assumam um papel mais ativo no planejamento da oferta de habitação popular e na alocação de terrenos para essa finalidade, o programa consolida um modelo em que a oferta de habitação se transforma fundamentalmente num negócio, sendo orientada por uma lógica em que a maximização dos ganhos das empresas se torna a principal condicionante do modo como os terrenos são escolhidos e de como os projetos são elaborados.

No caso da Faixa 1, a margem de lucro das empresas na produção de um empreendimento é determinada fundamentalmente por fatores como o custo de produção das unidades, o valor do terreno e o custo de infraestrutura e fundações demandado em função das características da gleba e sua localização. 0 programa estabelece um teto para o custo das unidades habitacionais, sendo esse valor diferenciado conforme o estado, o perfil dos municípios e a tipologia construtiva. ${ }^{7} 0$ objeto do contrato entre o FAR e a construtora pode abranger despesas com a aquisição do terreno, a implantação de infraestrutura interna e a construção das edificações e de equipamentos de uso comum, além de infraestrutura externa na poligonal do empreendimento nos casos envolvendo o parcelamento de glebas não urbanizadas. ${ }^{8}$ Esses custos precisam "caber na conta", ou seja, no valor do produto entre o número de unidades da operação e o teto do valor unitário financiável. Nessa equação, a receita da construtora contratada é invariável, de modo que sua margem de lucro depende dos custos mencionados. Ganhos na qualidade do projeto, no padrão construtivo e nos atributos urbanísticos do entorno dos empreendimentos são fatores que não exercem qualquer influência positiva sobre a taxa de retorno das construtoras, o que faz com que esses aspectos não sejam levados em conta. Esse desenho favorece também a proliferação de mega-empreendimentos. Embora tenham impactos urbanísticos muitas vezes desastrosos, os grandes conjuntos possibilitam ganhos de escala significativos para as construtoras, ampliando sua margem de lucro. ${ }^{9}$

A escolha dos terrenos pelas empresas, fator determinante para a taxa de retorno do empreendimento, segue uma equação complicada, sendo condicionada por variáveis como o custo do metro quadrado e as exigências estabelecidas na legislação quanto ao acesso a redes de infraestrutura, equipamentos e serviços. Devem ser periféricos o bastante para minimizar a porcentagem do investimento gasta com o terreno, mas não distantes a ponto de não atenderem às exigências mínimas para a aprovação de uma operação, ou demandarem custos adicionais com a expansão de redes de infraestrutura básica. ${ }^{10}$ Essa equação pode ser influenciada pela ação das prefeituras e governos estaduais que, além de doar terras públicas para a produção de empreendimentos de Faixa 1, podem complementar os subsídios disponibilizados pelo FAR por meio de contrapartidas financeiras, viabilizando a compra de terrenos mais caros e em tese melhor localizados, ou também custear a expansão de redes de infraestrutura, equipamentos e serviços, viabilizando a promoção de empreendimentos em áreas que a princípio não atenderiam às exigências mínimas do programa. ${ }^{11}$

A análise dos empreendimentos de Faixa 1 estudados nas regiões metropolitanas de São Paulo e de Campinas revelou dois padrões distintos de localização: 1) empreendimentos de grande porte, produzidos em grandes terrenos 
localizados em frentes de expansão nos limites da mancha urbana, predominantes na RMC; 2) empreendimentos de pequeno e médio porte, produzidos em terrenos menores (muitas vezes públicos) remanescentes em periferias consolidadas, predominantes na RMSP. 0 papel dos governos locais foi um fator relevante para a conformação desses padrões. Embora os impactos urbanísticos provocados pelos empreendimentos do PMCMV nessas duas regiões metropolitanas sejam qualitativamente distintos, nos dois casos o programa reitera processos históricos de segregação socioespacial ao reafirmar a lógica de assentamento da população de baixa renda em conjuntos habitacionais implantados em áreas periféricas, reproduzindo um padrão de apropriação desigual do espaço urbano, ainda que em patamares diferentes.

\section{A Região Metropolitana de Campinas: padrões de habitação e segregação}

A Região Metropolitana de Campinas (RMC), instituída por lei em 2000 e abrangendo 19 municípios, caracteriza-se pelo predomínio de um padrão de urbanização disperso. A dinâmica recente de ocupação de seu território foi impulsionada pela constituição de núcleos populacionais, bairros, empreendimentos industriais e polos de serviços espalhados ao longo de extensos eixos rodoviários, em geral distantes das áreas de urbanização mais antiga (Caiado e Pires, 2006). Esse modelo de desenvolvimento urbano favoreceu o estabelecimento de uma dinâmica metropolitana marcada pela necessidade de grandes deslocamentos, que estimula fortemente o uso do automóvel como meio de transporte.

À exceção do centro expandido do município de Campinas, onde se observa um padrão urbano mais compacto, essa região metropolitana apresenta uma malha descontínua. Predominam núcleos dispersos, conectados a eixos viários arteriais que se irradiam a partir da área central de Campinas e aos anéis rodoviários que ligam as diversas estradas da região. Prevalece um padrão de uso do solo de caráter eminentemente monofuncional, com forte predominância do uso residencial e uma presença incipiente de atividades comerciais, serviços e equipamentos culturais.

Além da expressiva dispersão territorial, a RMC tem como uma de suas características principais a presença de um padrão de segregação socioespacial marcado pela existência de duas grandes áreas bem distintas do ponto de vista socioeconômico (Cunha et al., 2006). Na escala metropolitana, a linha divisória entre elas é definida pela Rodovia Anhanguera, que estabelece uma fronteira entre uma porção nordeste rica e uma porção sudoeste pobre.

0 contraste entre essas duas porções da RMC pode ser observado a partir de indicadores como o Índice Paulista de Vulnerabilidade Social - IPVS (Fundação Seade, 2009), a renda domiciliar média e a concentração de áreas classificadas como "aglomerados subnormais" pelo IBGE. A porção sudoeste do Município de Campinas, abrangendo bairros como o Campo Grande, assim como alguns dos municípios adjacentes, como Hortolândia, Monte-Mor, Sumaré e Santa Bárbara d'Oeste, caracteriza-se como um território eminentemente popular. Nessa região, onde se concentram os principais bolsões de pobreza da RMC, há uma incidência 
expressiva de áreas classificadas pela Fundação Seade como de alto índice de vulnerabilidade social. Observa-se também indicadores de renda domiciliar média significativamente inferiores aos do restante da região metropolitana. Essa é a região caracterizada pela presença massiva de conjuntos habitacionais de grande porte, loteamentos de baixo padrão e assentamentos autoconstruídos, tendo se constituído historicamente como o lugar dos pobres na RMC.

A porção nordeste da RMC, por sua vez, é a área onde se concentram os segmentos sociais de maior poder aquisitivo. Nessa região, estão situados os bairros de alta renda do $\mathrm{Mu}$ nicípio de Campinas, além dos vetores de expansão urbana de alto padrão, localizados ao longo de eixos viários que conectam Campinas aos municípios vizinhos de Paulínia, Jaguariúna e Holambra e do anel rodoviário que circunda o núcleo central da região metropolitana. Essa porção do território é também a que apresenta maior disponibilidade de empregos, serviços e equipamentos urbanos em geral.

A política habitacional desempenhou papel relevante na consolidação do modelo de urbanização disperso que caracteriza a expansão recente dessa região metropolitana, assim como no estabelecimento de seu padrão de segregação socioespacial. A construção de grandes conjuntos habitacionais por empresas públicas em áreas periféricas onde a terra é mais barata representou a forma de provisão habitacional predominante ao longo de décadas, contribuindo substancialmente para impulsionar o espraiamento urbano e para estabelecer uma divisão entre o lugar dos ricos e o lugar dos pobres na cidade assentando-se os moradores de baixa renda em periferias monofuncionais e homogêneas, com pouca oferta de emprego, condições precárias de infraestrutura, oferta insatisfatória de equipamentos e serviços urbanos e sérias restrições de mobilidade.

Além disso, a ausência de programas habitacionais direcionados à população de baixíssima renda num contexto de crescimento demográfico acelerado acarretou a proliferação de um universo expressivo de assentamentos precários e irregulares concentrados majoritariamente na porção sudoeste da região metropolitana, onde o interesse do mercado imobiliário é menor e a tolerância em relação à informalidade na ocupação do solo é maior.

\section{Empreendimentos do PMCMV na Região Metropolitana de Campinas}

A RMC foi uma das regiões do país onde o PMCMV alcançou os resultados mais expressivos do ponto de visto quantitativo. Na primeira fase do programa, foram produzidas mais de 20 mil U.H. A produção total aumentou $23 \%$ na segunda fase, e o número de U.H. da Faixa 1 dobrou, conforme sintetizado no gráfico abaixo. Os números expressivos alcançados pelo programa na região devem-se principalmente à existência de alguns conjuntos que podem ser caracterizados como megaempreendimentos. 
Figura 1 - Unidades habitacionais produzidas

na Região Metropolitana de Campinas nas duas fases do programa MCMV

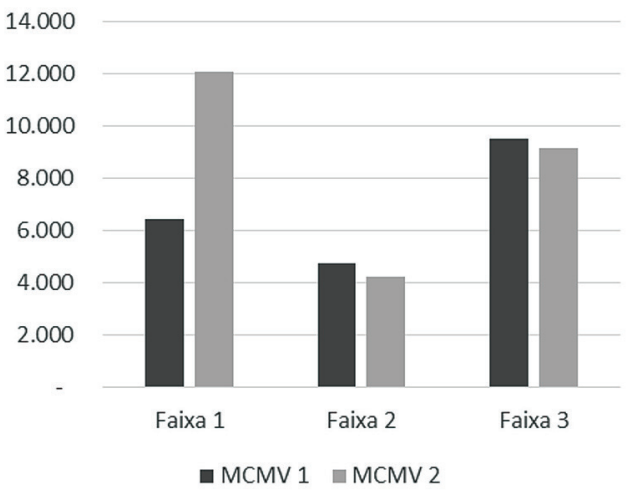

\section{Porte dos empreendimentos e tipologia}

Durante o trabalho de mapeamento das operações do PMCMV, deparou-se com uma situação recorrente que impôs desafios metodológicos para a análise do porte dos empreendimentos. Foram identificados diversos casos de operações adjacentes promovidas por uma mesma construtora que, se consideradas individualmente, caracterizariam conjuntos de porte moderado. No entanto, se observadas em conjunto, essas operações conformariam empreendimentos de porte bem maior. Avaliou-se que, para retratar a distribuição dos conjuntos do programa por faixas de porte, seria mais

\begin{tabular}{c|c|c|c} 
& Faixa 1 & Faixa 2 & Faixa 3 \\
\hline MCMV 1 & 6.416 & 4.752 & 9.500 \\
\hline MCMV 2 & 12.065 & 4.243 & 9.162 \\
\hline Total & 18.481 & 8.995 & 18.662
\end{tabular}

importante levar em conta sua materialidade urbanística do que simplesmente processar informações constantes numa tabela com dados formais das operações. Definiu-se, assim, a categoria de "empreendimentos contíguos", produzindo-se dados de porte a partir da agregação das unidades habitacionais integrantes das operações contíguas como se formassem um mesmo empreendimento. ${ }^{12}$

Levando-se em conta apenas os dados fornecidos pela CAIXA, a maioria dos empreendimentos, 47\%, tem entre 101 e 300 unidades, e uma pequena parcela, $9 \%$ do total, tem mais de 500 U.H.. Entretanto, ao se considerar os casos de contiguidade, constata-se que a maioria dos empreendimentos teria entre 301 e 1.500 U.H. e, além disso, 32\% teriam mais de 500 U.H. 
Figura 2 - Distribuição dos empreendimentos de acordo com seu porte individual e com o porte considerando os casos de contiguidade.

\section{Empreendimentos da RMC}

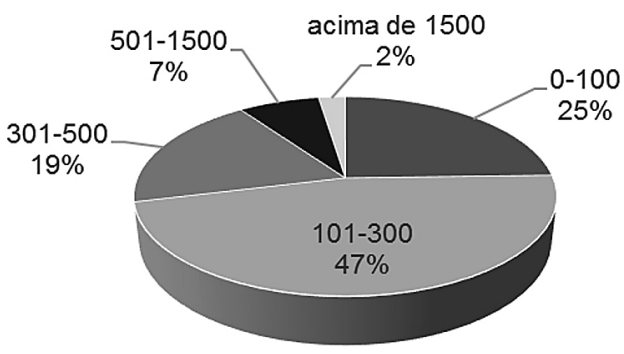

Considerando a contiguidade, os 163 empreendimentos formalmente contratados se reduziriam a 89 empreendimentos. A análise revelou que a maior parte dos empreendimentos da região está inserida em "megaempreendimentos", favorecendo a constituição de tecidos urbanos homogêneos tanto em termos de renda quanto em termos de tipologia e uso. Da totalidade de unidades habitacionais produzidas, $86 \%$ integram condomínios ou loteamentos com mais de 500 U.H. se considerarmos a contiguidade.

A fim de realizar uma aproximação geral ao padrão tipológico empregado pelas construtoras no PMCMV, foram definidas quatro categorias de tipologia arquitetônica: casas, blocos (edificações sem elevador com até cinco pavimentos, incluindo o térreo), torres (edificações com mais de 5 cinco pavimentos)

\section{Simulação de contíguos na RMC}

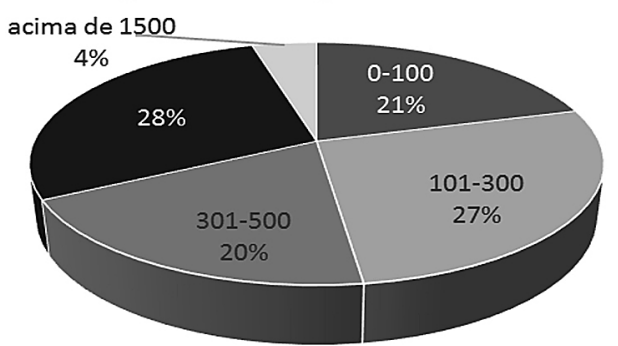

e empreendimentos mistos (abrangendo duas ou mais dessas categorias numa única operação). Constatou-se que aproximadamente $60 \%$ dos empreendimentos da RMC apresentam tipologia de bloco, sendo a grande maioria deles empreendimentos implantados em grandes glebas de uso exclusivamente residencial, sob a forma de condomínio. Constatou-se também uma presença considerável de casas, $21 \%$, também majoritariamente localizadas em áreas de uso exclusivamente residencial. ${ }^{13}$ As torres respondem por $16 \%$ dos empreendimentos. Os empreendimentos desse tipo tendem a ser melhor inseridos, localizando-se em áreas mais centrais, próximas a oferta de emprego, infraestrutura e equipamentos $\mathrm{e}$, portanto, em áreas onde 0 preço da terra é maior e a ocupação do solo é mais intensiva. 


\section{Inserção regional dos empreendimentos}

Observando-se os mapas a seguir, nota-se que o número de empreendimentos localizados na porção nordeste da região metropolitana, onde se dispõe de melhores condições urbanas, é bastante reduzido. Entre os poucos empreendimentos situados nessa área, quase todos são destinados às faixas de renda mais elevadas, sendo a maioria da
Faixa 3. Em geral, são empreendimentos de porte pequeno se comparados àqueles situados nas franjas urbanas, representando um percentual pouco expressivo do total de unidades habitacionais produzidas na RMC no âmbito do PMCMV.

A situação é bem diferente na porção sudoeste da RMC. Nesse setor, encontram-se empreendimentos das três faixas do programa. No entanto, quase todos os empreendimentos destinados à Faixa 1 localizam-se nessa porção do território metropolitano.

\section{Mapa 1 - Empreendimentos do MCMV por faixa da RMC sobre rendimento domiciliar médio mensal. \\ Destaque para as áreas onde o IPVS é mais grave: valores de 5,6 e 7 em uma escala de 1 a 7}

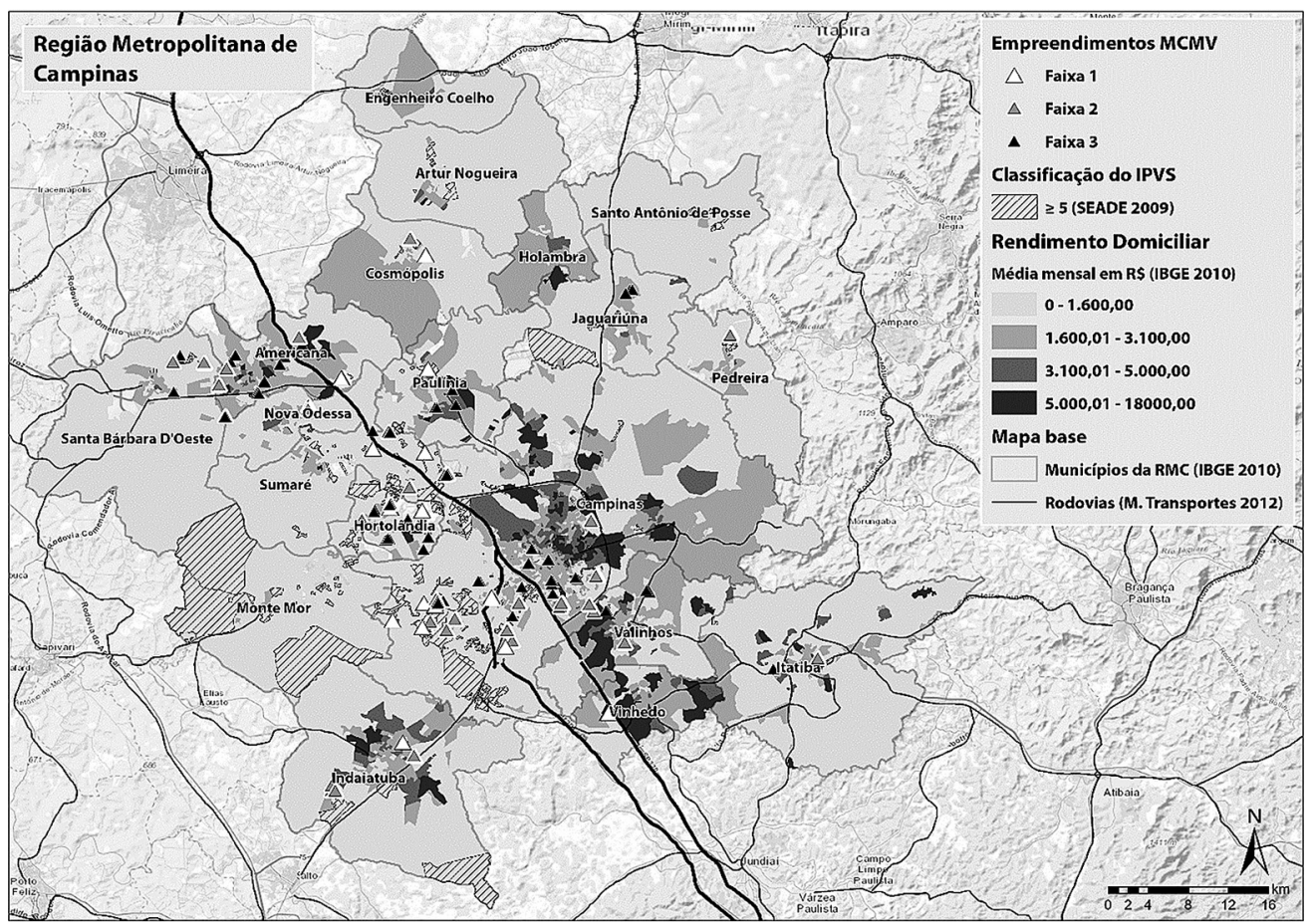


Nesta área, estão concentrados os empreendimentos de grande porte e os maiores agrupamentos de conjuntos habitacionais da RMC. Ao contrário do que ocorre em sua porção nordeste, onde a maioria dos empreendimentos ocupam terrenos menores, em geral preenchendo vazios remanescentes de uma malha urbana de densidade moderada, muitos dos empreendimentos da porção sudoeste estão localizados em grandes glebas nos limites da mancha urbanizada, provocando sua extensão para áreas cada vez mais distantes, geralmente com oferta significativamente limitada de equipamentos urbanos, serviços públicos e empregos. Em algumas situações, observa-se a aglomeração de diversos empreendimentos numa mesma região, formando verdadeiros bolsões de moradia popular, bastante semelhantes às cidades dormitórios que foram constituídas pela produção habitacional pública em décadas anteriores.

\section{Mapa 2 - Porte dos empreendimentos da RMC}

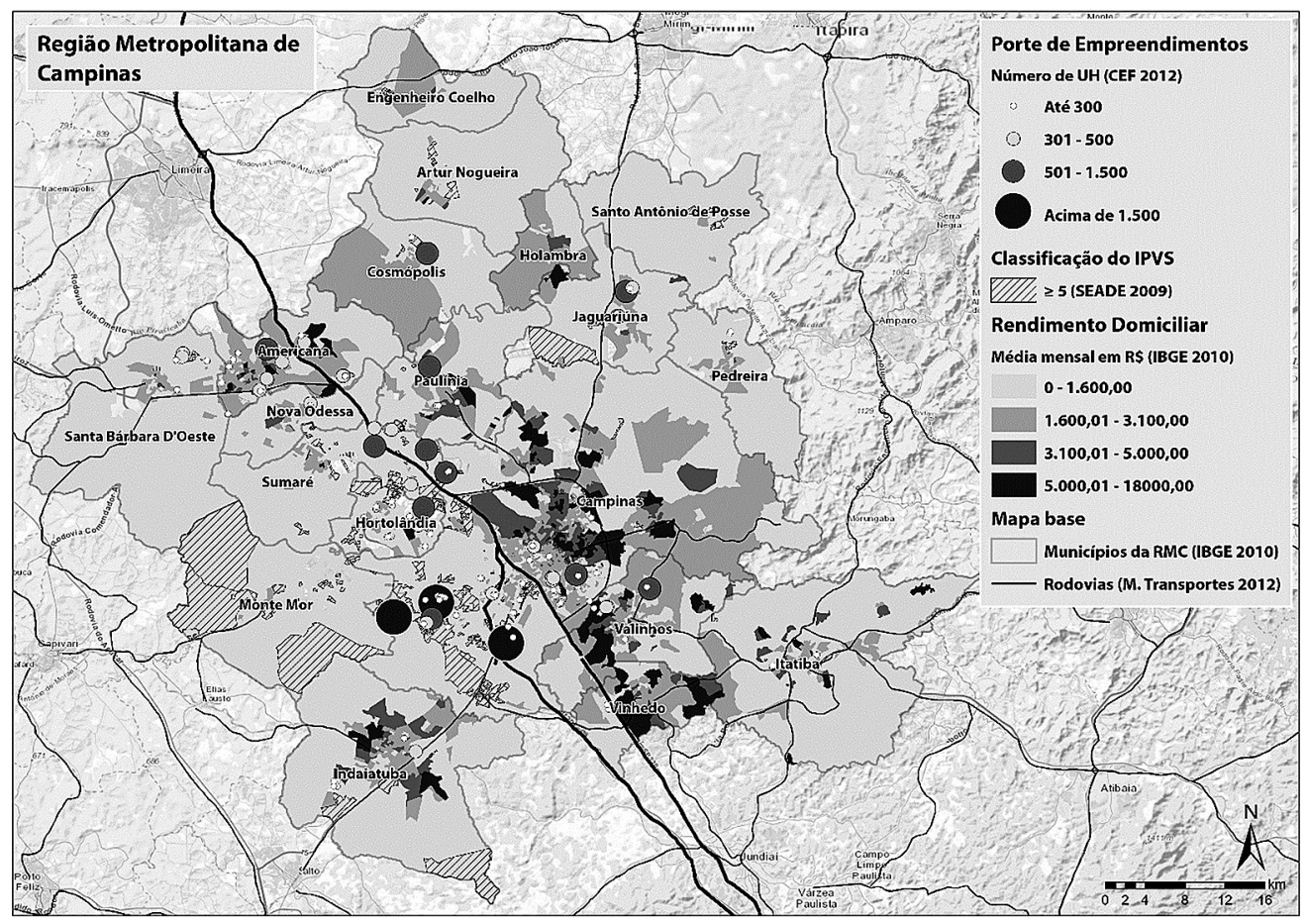




\section{Mapa 3 - Tipologia dos empreendimentos do MCMV na RMC}

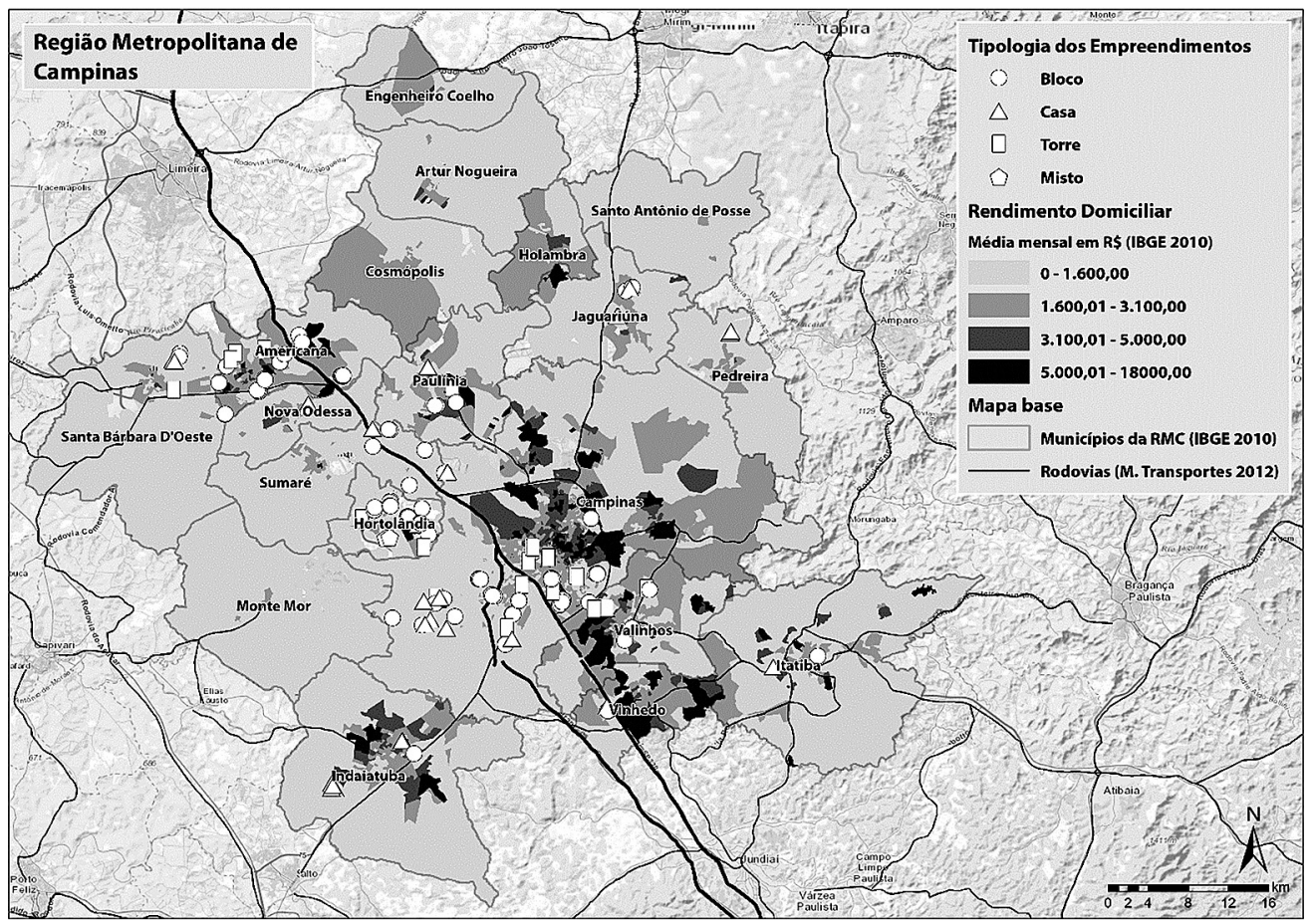

Ressalta-se que não foram identificados empreendimentos completamente desconectados do tecido urbano constituído. Isso é um aspecto que diferencia o padrão locacional dos empreendimentos do PMCMV daquele vigente em contextos anteriores, em que os conjuntos de moradia popular eram frequentemente implantados em meio rural, abrindo frentes pioneiras de ocupação do território. Por outro lado, identificou-se um conjunto expressivo de empreendimentos situados nos limites da mancha urbanizada, contribuindo para impulsionar sua expansão e reforçando o modelo de urbanização dispersa da RMC.

Essa tendência fica clara ao se observar os empreendimentos da Faixa 1 do programa - majoritariamente localizados nas áreas mais precárias da RMC e agrupados em vetores quase que exclusivamente ocupados por grandes conjuntos de moradia popular. 0 padrão urbanístico desses empreendimentos pode ser observado nas imagens da Foto 1.

Trata-se de concentração de um conjunto expressivo de empreendimentos de grande porte, com tipologia padronizada e destinados a uma mesma faixa de renda, inseridos num tecido urbano monótono com pouca diversidade de usos - ainda que agora se disponha de um mínimo de equipamentos e serviços básicos no entorno ou em bairros vizinhos. 
Foto 1 - Empreendimentos contíguos Peruíbe e Praia Grande na cidade de Hortolândia, Região Metropolitana de Campinas.

Somados, possuem 500 unidades habitacionais
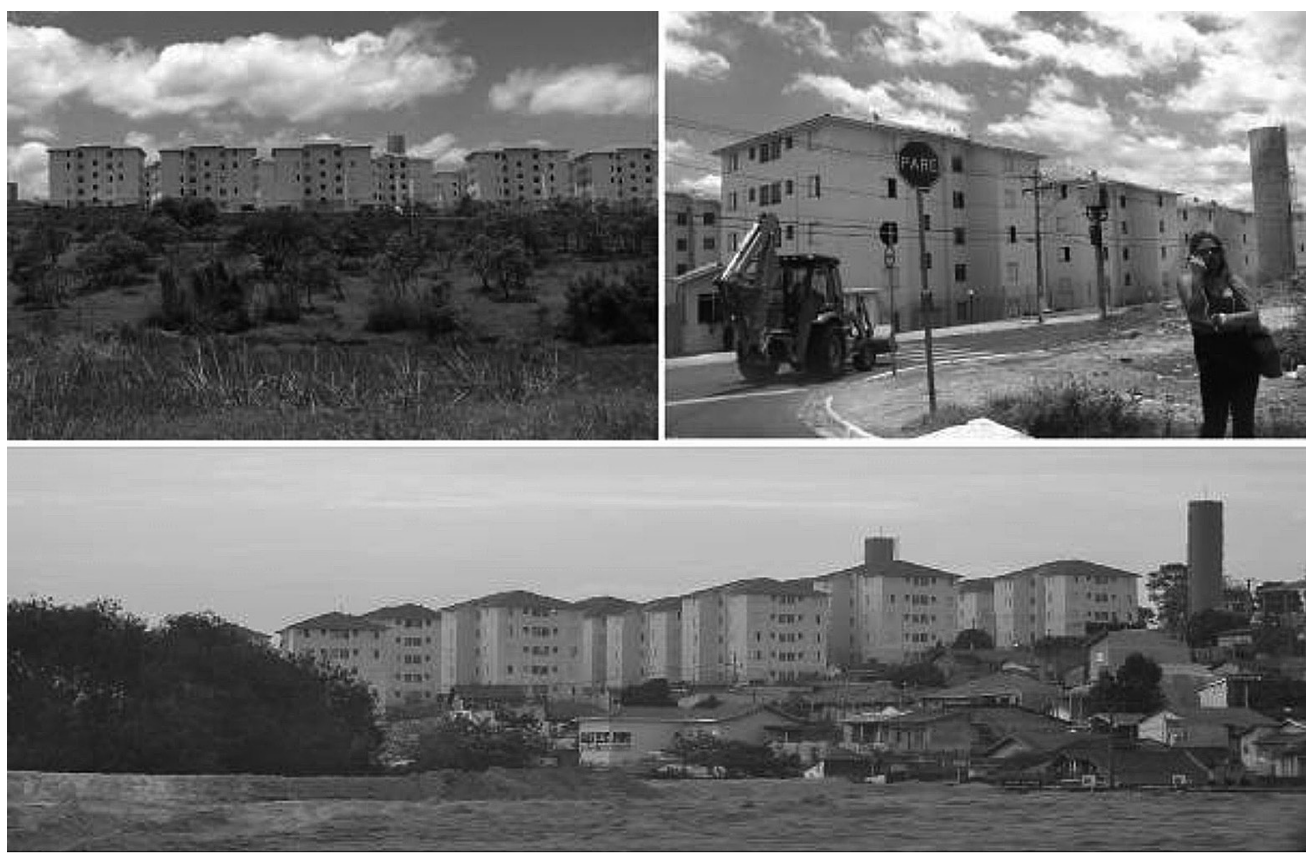

\section{Região Metropolitana de São Paulo: padrões de habitação e segregação}

A Região Metropolitana de São Paulo (RMSP), instituída por lei em 1973, é composta por 39 municípios, e tem no município de São Paulo seu principal polo populacional e econômico. Essa forte polarização do município de São Paulo expressou-se territorialmente em seu quadrante sudoeste, que historicamente concentrou a renda e o emprego na cidade (Villaça, 1998; Rolnik e Frúgoli Jr., 2001). Já o desenvolvimento da periferia se deu com a ocupação de população de menor renda, tanto no muni- cípio de São Paulo quanto nos circundantes. 0 padrão centro-periferia constituído ao longo do século XX guarda hoje, entretanto, heterogeneidades internas tanto nos territórios centrais como na periferia, com características e dinâmicas complexas e especificas em suas sub-regiões (Marques e Torres, 2005; Moya, 2011).

A intensa migração interna brasileira, mais forte a partir da industrialização de São Paulo, e o crescimento populacional de estratos de baixa renda, foram consolidando uma ocupação autoconstruída nas bordas da cidade, especialmente em suas porções leste e sul (Bonduki e Rolnik, 1979; Maricato, 1996; Taschner, 2001). Esse intenso crescimento metropolitano gerou também outras 
centralidades, subcentros metropolitanos com dinâmicas próprias. Parques industriais importantes se estabeleceram na RMSP, como o polo industrial do $A B C D$, Osasco e Guarulhos, situadas a oeste e a nordeste do município de São Paulo respectivamente. Nessas mesmas regiões, desenvolveram-se subcentros metropolitanos que hoje têm grande presença de atividades terciárias.

Apesar de menos acelerado do que na década anterior, o crescimento demográfico das áreas periféricas, mais pobres e mais carentes de infraestrutura, ainda é maior do que no restante da região metropolitana. 0 incremento populacional tem sido mais intenso nas fronteiras urbanas (Torres, 2005), o que agrava a demanda por equipamentos, serviços e empregos. Como mostraremos a seguir, os empreendimentos do PMCMV, sobretudo aqueles destinados à Faixa 1 vêm se concentrando em terrenos remanescentes localizados nas áreas historicamente ocupadas pela população de baixa na RMSP.

\section{Empreendimentos do PMCMV na RMSP}

A produção do programa Minha Casa Minha Vida na RMSP decresceu 7\% entre a fase 1 e a fase 2.

Diferentemente do comportamento observado na RMC, em que o programa tem um direcionamento muito forte para a produção da Faixa 1, na RMSP observa-se um certo equilíbrio na produção das Faixas 1 e 2 nas duas fases do programa. Por outro lado, percebe-se uma significativa redução da produção da Faixa 3 em sua segunda fase.

Figura 3 - Unidades habitacionais produzidas na Região Metropolitana de São Paulo nas duas fases do programa MCMV

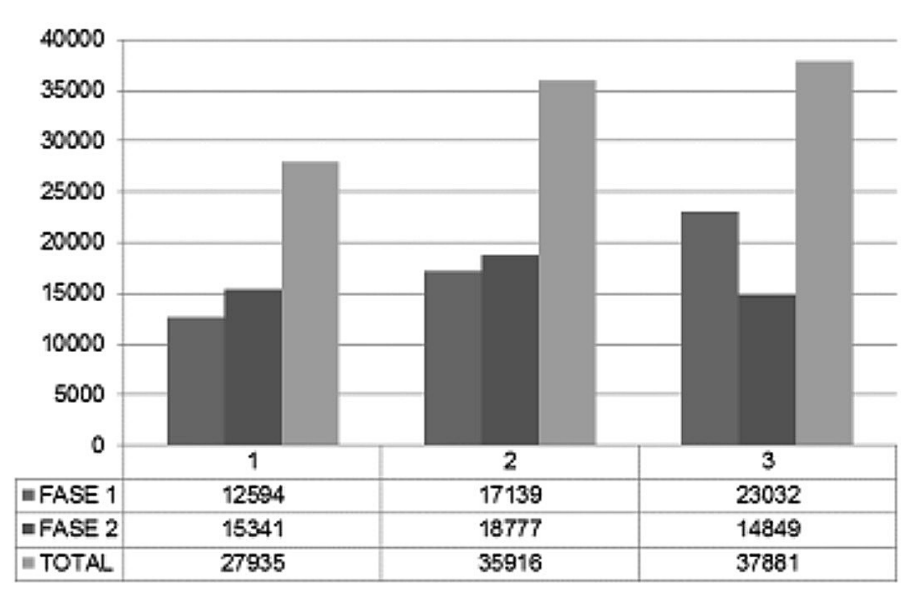




\section{Porte dos empreendimentos e tipologia}

Considerando os critérios já apresentados na análise do porte dos empreendimentos na RMC, foi observado que na RMSP a maioria dos empreendimentos, 59\%, tem entre 101 e 300 unidades habitacionais, enquanto uma pequena parcela, $3 \%$ do total, tem mais de 500 U.H.. Ao analisar a distribuição do porte dos empreendimentos considerando a contiguidade, entretanto a RMSP passa a ter $11 \%$ de empreendimentos com mais de 500 U.H.

Em geral, os empreendimentos da RMSP apresentam porte menor do que os da RMC.
Isso ocorre porque o acesso à terra é mais difícil, tanto em função do valor do solo quanto da disponibilidade de terrenos nos municípios. 0 alto grau de conurbação e a densidade de ocupação do território impossibilitam a disseminação de "megaempreendimentos" semeIhantes àqueles encontrados na RMC.

0 resultado do levantamento de tipologias mostra haver um equilíbrio entre duas tipologias principais, ambas verticais: $45 \%$ das U.H. são em blocos e $51 \%$ U.H. em torres. Há uma porcentagem muito reduzida de empreendimentos do tipo casa, o que reflete a escassez de terras e a tendência de formas mais intensivas de uso do solo.

Figura 4 - Gráficos com a distribuição dos empreendimentos da RMSP de acordo com seu porte individual e com o porte considerando os casos de contiguidades

\section{Empreendimentos da RMSP}

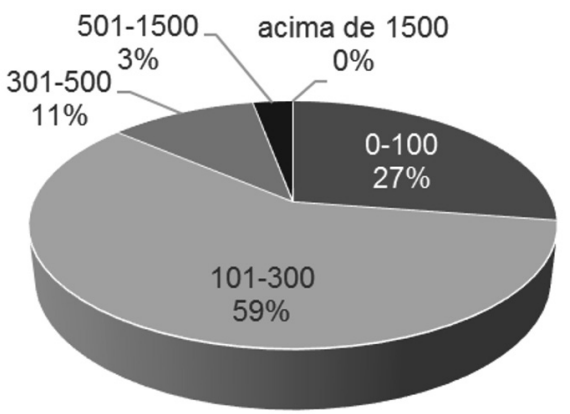

\section{Simulação de contíguos na RSMP}

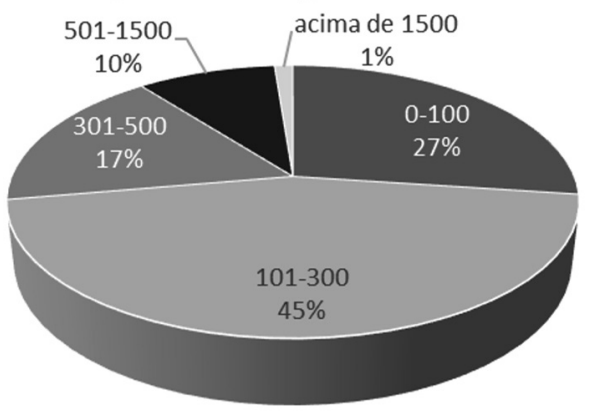




\section{Inserção regional dos empreendimentos}

Os empreendimentos da Faixa 1 na RMSP estão localizados em sua maioria nos municípios de sua porção leste e no extremo da Zona Leste do próprio município de São Paulo, em especial no distrito de Cidade Tiradentes. Há também um número significativo de conjuntos em torno do trecho oeste do Rodoanel, no Jardim Ângela (Zona Sul da capital) e na região do $A B C D$. Mais de $48 \%$ das U.H. produzidas para a Faixa 1 na RMSP estão nos municípios de Guarulhos, Suzano, Mogi das Cruzes, Itaquaquecetuba e
Guararema. Se somarmos a esses as unidades da Faixa 1 do município de São Paulo, 79\% das U.H. dessa faixa estão localizadas na porção leste da RMSP.

Importante notar que o centro expandido do município de São Paulo não teve nenhum empreendimento da Faixa 1 contratado até dezembro de 2012. Já os empreendimentos das Faixas 2 e 3 localizam-se predominantemente na periferia do centro expandido e nos eixos das linhas férreas que seguem para a Zona Leste e para o $A B C$ (eixo do rio Tamanduateí). Identificou-se um padrão de localização semeIhante entre as Faixas 2 e 3.

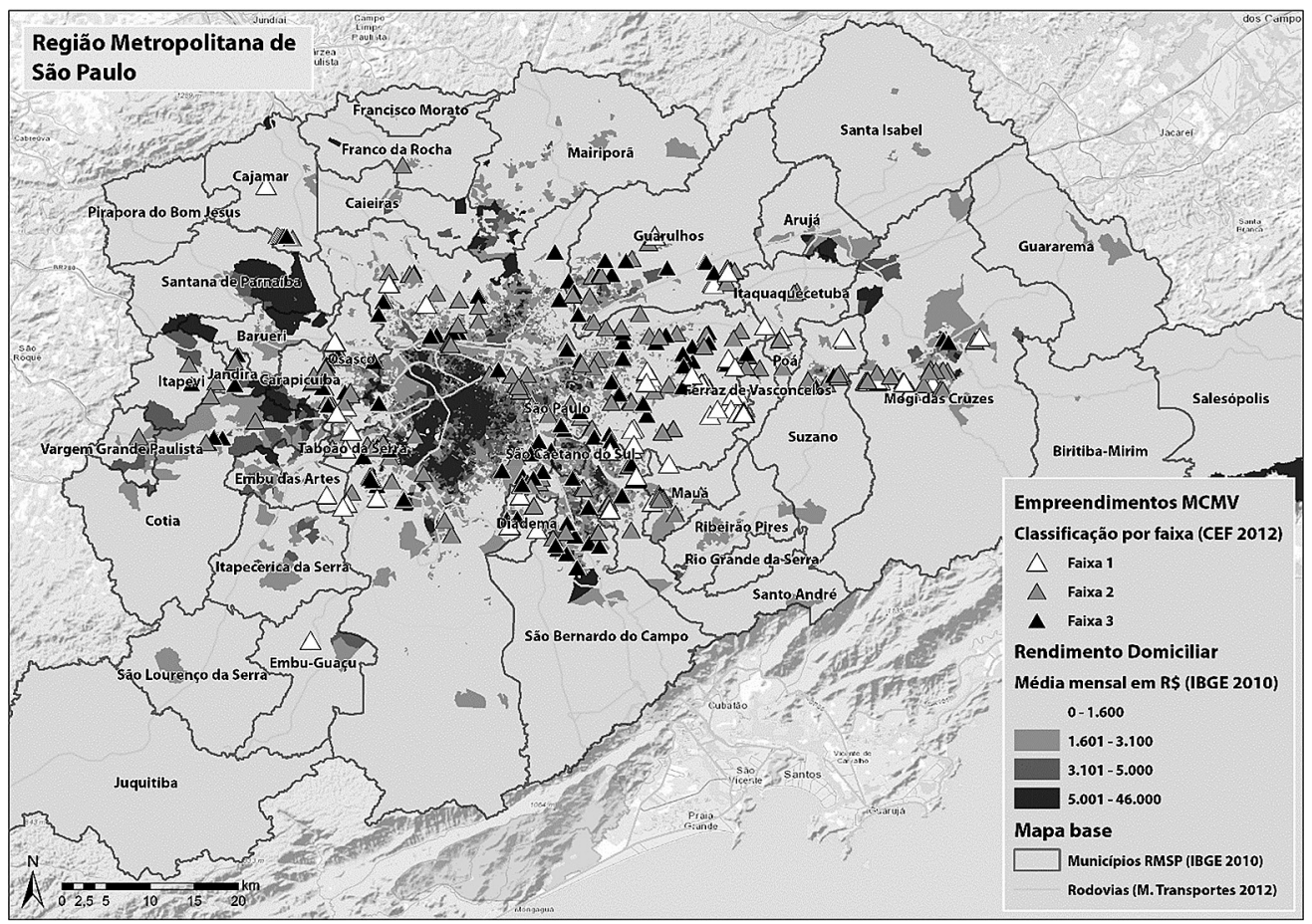


Analisando as sub-regiões, identificaram-se três situações de destaque com uma concentração significativa de empreendimentos: a primeira delas a oeste, ao longo do Rodoanel; a segunda a leste, acompanhando a Linha Coral do trem da CPTM, e uma terceira nos municípios do $A B C D$. Nota-se que, nessas três situações, foi identificada a ocorrência de empreendimentos das três faixas, apesar da predominância das Faixas 2 e 3. Identifica-se, ainda, grandes empreendimentos contíguos nos municípios de Mogi das Cruzes, Mauá, Cajamar e Guarulhos, que apresentam índices de vulne- rabilidade elevados, conforme Índice Paulista de Vulnerabilidade Social (IPVS). ${ }^{14}$

0 Mapa 5, cruzando o IPVS com a localização dos empreendimentos, ajuda a visualizar a contribuição do programa para reforçar os padrões de segregação socioespacial dessa região metropolitana. Percebe-se que a grande maioria dos empreendimentos de Faixa 1 está em áreas de alta vulnerabilidade social, coincidindo também com o 'anel' de áreas classificadas como "aglomerados subnormais" pelo IBGE (Censo de 2010), como pode ser observado no Mapa 6.

\section{Mapa 5 - Empreendimentos do MCMV na RMSP \\ por faixas sobre IPVS da Fundação Seade}

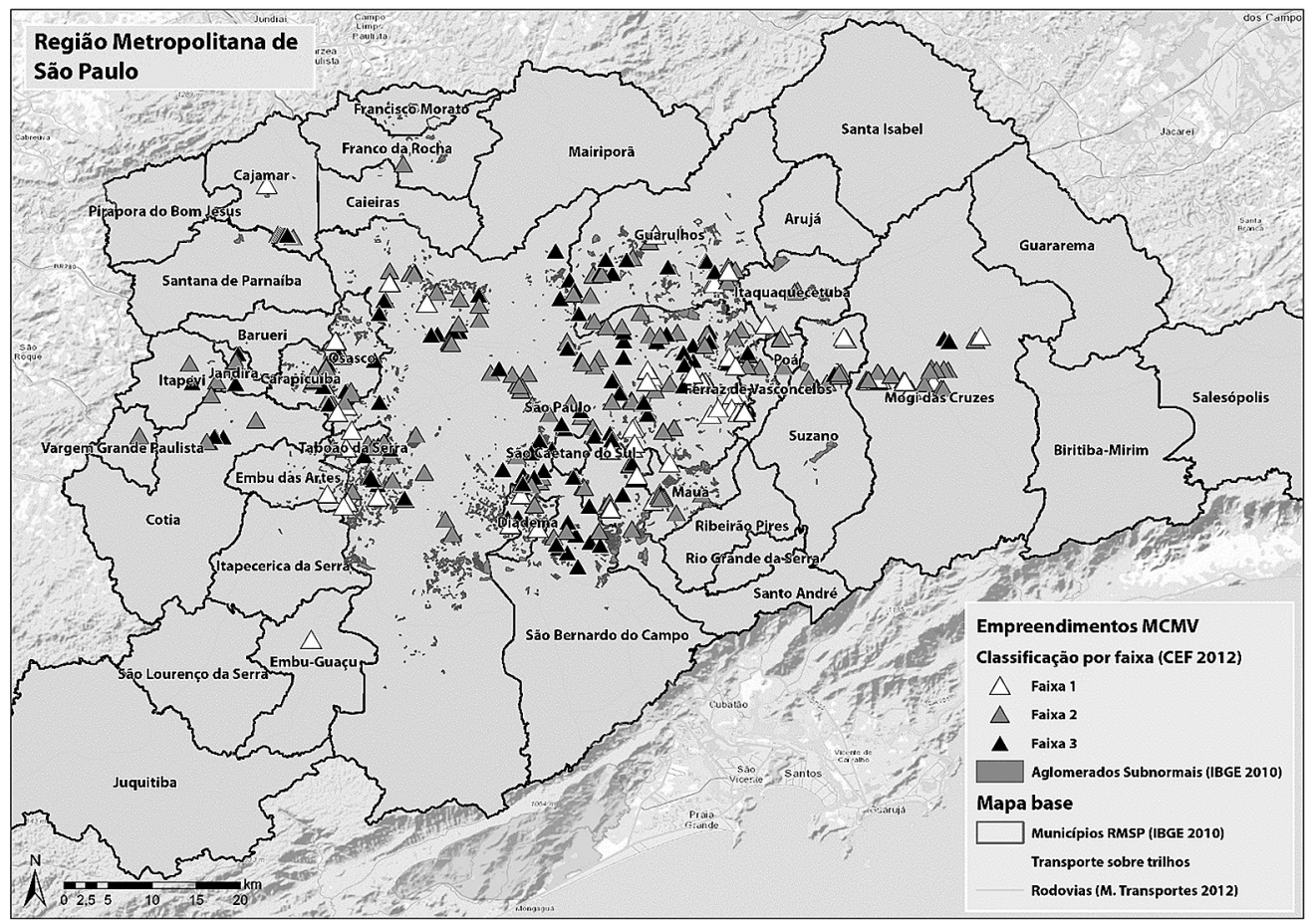


Mapa 6 - Empreendimentos do MCMV por faixa e distribuição dos aglomerados subnormais definidos pelo IBGE

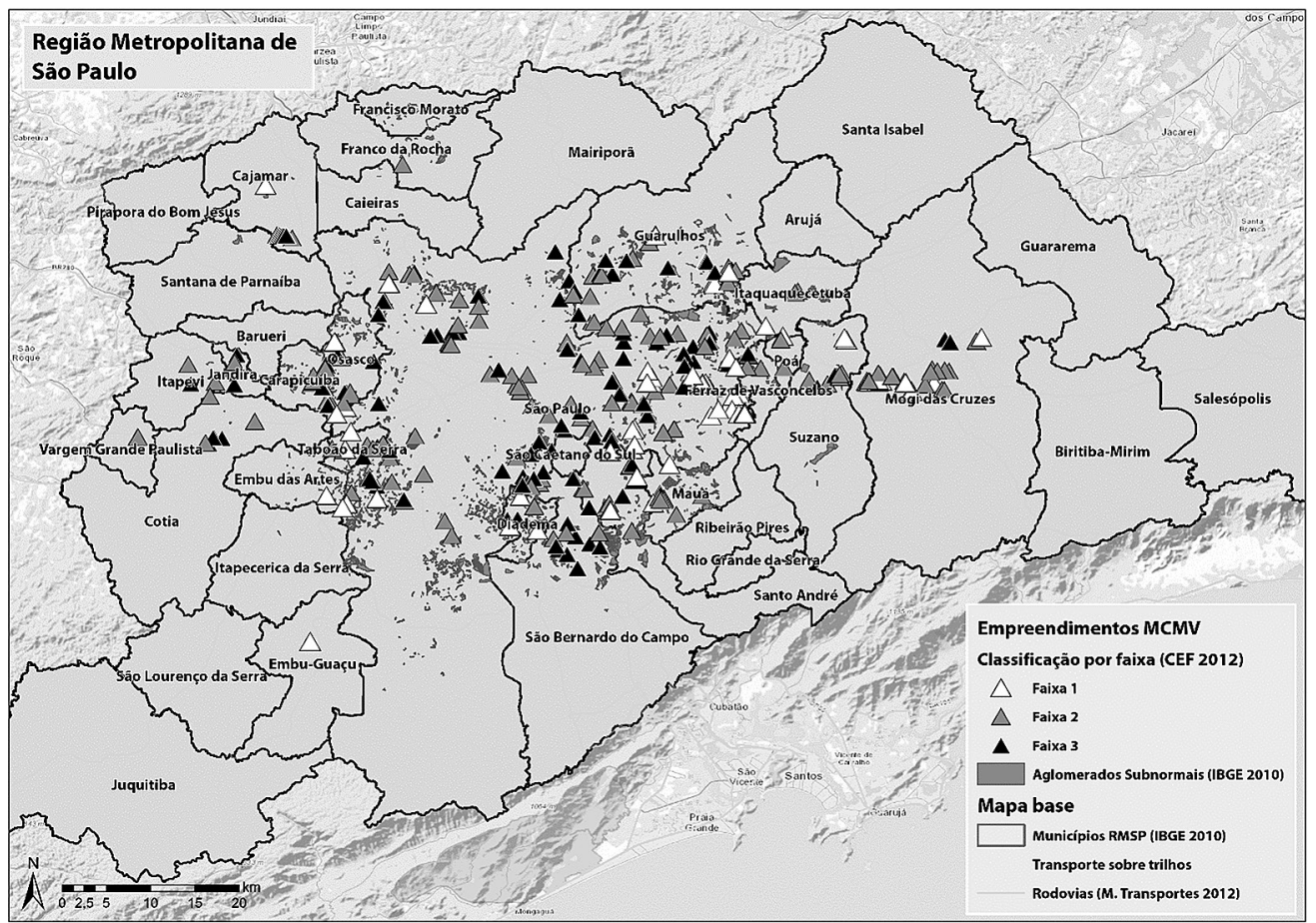

0 Mapa 7, cruzando a tipologia dos empreendimentos com a renda domiciliar média, evidencia a maior incidência de blocos nas áreas mais periféricas e a maior presença de torres nas áreas mais centrais.

Quando se observa o mapa de densidade de emprego, produzido a partir dos dados da Pesquisa Origem Destino de 2007 (Mapa 8), percebe-se que a concentração dos empregos ainda é bastante forte no vetor sudoeste do município de São Paulo, revelando a polarização da RMSP em torno dessa área da capital. No entanto, outras centralidades, como o eixo do $A B C D$ a sudeste, Guarulhos a nordeste e Osasco-Barueri a noroeste da região metropolitana, se destacam como importantes centros de emprego e serviços, qualificando São Paulo como uma metrópole multipolar.

A característica de metrópole multipolar, com várias centralidades, não exclui a característica histórica da periferia metropolitana como o lugar dos pobres na cidade, condição que se intensificou com o aumento populacional e a consolidação de forma precária em termos de infraestrutura, acesso a equipamentos e serviços. A periferia da RMSP é atualmente uma 
área com oferta de comércio e serviços, porém com um padrão urbanístico precário, com infraestrutura de baixa qualidade, que vem crescendo em termos populacionais, criando subcentralidades importantes, mas que não rompem com os padrões de desenvolvimento desigual e segregação socioespacial característicos dessa metrópole. É justamente nessas áreas que se encontram os maiores agrupamentos de empreendimentos, conforme se vê no Mapa 8, o que evidencia o reforço desse padrão pelo programa.

Mapa 7 - Empreendimentos na RMSP de acordo com sua tipologia

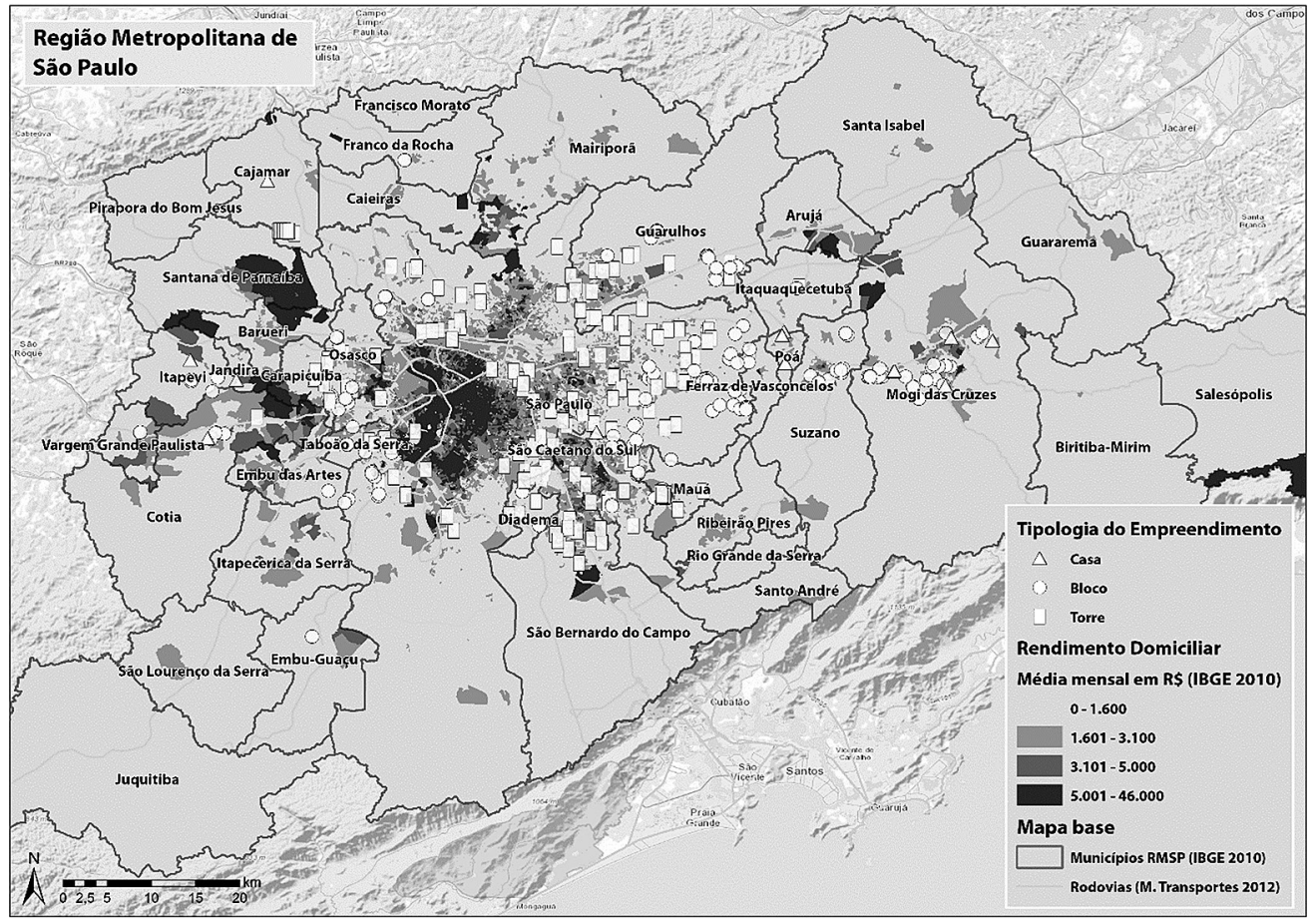


Mapa 8 - Densidade de empregos (Pesquisa OD 07 - Metrô de São Paulo) e distribuição dos agrupamentos de empreendimentos de acordo com a quantidade de U.H. em cada um. Cada agrupamento foi definido por um conjunto de empreendimentos que têm, no máximo, 500m de distância entre si

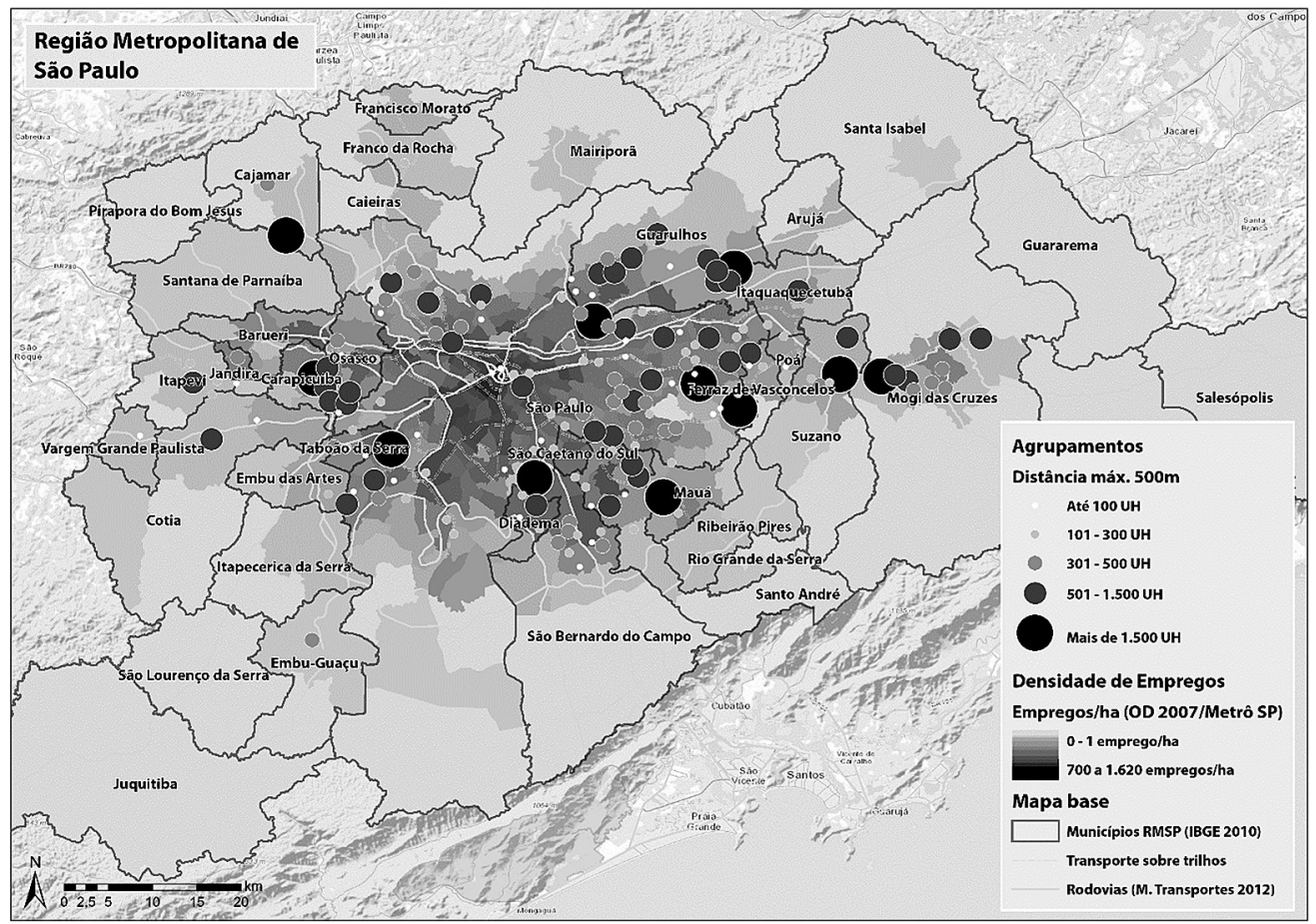

\section{Considerações finais}

Analisamos neste artigo o padrão de inserção urbana dos empreendimentos do PMCMV nas regiões metropolitanas de São Paulo e Campinas, cruzando dados de porte, tipologia e faixa de renda dos conjuntos produzidos com indicadores de renda domiciliar média, oferta de emprego e vulnerabilidade social nos respectivos territórios. Constatou-se que o programa reitera uma série de características do processo de urbanização dessas regiões metropolitanas, marcadas historicamente pela segregação socioespacial, reforçando a lógica de que o lugar dos pobres é nas periferias, o que se verificou especialmente no caso dos empreendimentos destinados à Faixa 1.

Embora no atual contexto essas regiões metropolitanas sejam mais multipolares do que em décadas anteriores, e a precariedade de suas áreas periféricas, tendo passado por um processo cumulativo de consolidação, seja menos extrema, a segregação continua sendo uma característica central de sua configuração 
socioespacial. Essas regiões metropolitanas continuam apresentando uma periferia habitada predominantemente por uma população de baixa renda, com pouca diversidade funcional, um tecido urbano fragmentado e carência de infraestrutura, equipamentos, serviços públicos e empregos.

No caso da RMC, o padrão de inserção urbana dos empreendimentos do PMCMV apresenta maior semelhança com o padrão de produção de HIS em São Paulo entre os anos 1970 e 1980, quando imensos aglomerados de conjuntos habitacionais da Cohab - o mais emblemático deles é Cidade Tiradentes - foram construídos fora da malha urbana, em áreas sem infraestrutura adequada, sem espaços comerciais ou equipamentos públicos, precariamente conectados ao tecido urbano e com condições inadequadas de transporte público e mobilidade. A intensa produção de moradia sem cidade naquele período acabou por gerar ampla segregação e uma série de problemas sociais que trouxeram ônus significativos para o poder público ao longo das décadas seguintes, fenômeno que está se repetindo em parte da produção do programa. Cabe ressaltar que, naquele período, o rápido crescimento populacional nas grandes metrópoles do país, fruto de um crescimento demográfico acelerado e do forte êxodo rural, impulsionou um crescimento urbano desordenado, impondo sérias dificuldades para o assentamento da população em condições satisfatórias. No atual momento histórico, entretanto, com taxas de crescimento demográfico menores, maior disponibilidade de recursos públicos e estágios de urbanização mais consolidados nas metrópoles do país, prover moradia com urbanidade é algo mais factível do que nas décadas anteriores.
No caso da RMSP, a inserção de empreendimentos do PMCMV se deu predominantemente em periferias consolidadas, nas reservas de terra remanescentes dos conjuntos produzidos em décadas anteriores. Trata-se de glebas menores, sobras dos conjuntos habitacionais mencionados. Se antes essas áreas estavam fora da malha urbana, hoje esses terrenos estão situados numa periferia consolidada, servida por equipamentos sociais e inserida num tecido que se consolidou a partir de um padrão de urbanização bastante precário e fragmentado. Embora atualmente essas áreas já tenham uma dinâmica urbana própria, dispondo de subcentralidades e de alguma diversidade de comércio e serviços, indicadores como o IPVS, a renda domiciliar e a densidade de empregos mostram que essas localidades ainda são bastante homogêneas e precárias, oferecendo poucas oportunidades de desenvolvimento econômico e cultural a seus moradores, mantendo características de bairros-dormitório.

A política habitacional desempenhou historicamente um papel central na consolidação do modelo urbano dessas regiões metropolitanas, assim como na reprodução de seu padrão de segregação socioespacial. A construção de grandes conjuntos habitacionais em áreas periféricas onde a terra é mais barata, representando a forma de provisão habitacional predominante ao longo de décadas, contribuiu substancialmente para impulsionar o espraiamento urbano, a proliferação de um padrão urbanístico monofuncional e o estabelecimento de uma divisão territorial entre ricos e pobres.

Ressalta-se que muitos dos problemas apontados nos conjuntos do PMCMV neste artigo, tais como suas tipologias arquitetônicas, padrões de desenho urbano e escalas de 
produção, não são uma exclusividade do programa, mas traços generalizados da produção do espaço nas cidades brasileiras. Contudo, um programa habitacional dessa dimensão poderia ser um importante vetor de qualificação de áreas precárias e de promoção de um modelo mais igualitário de ocupação do território ao invés de potencializar problemas urbanos e reafirmar disparidades socioespaciais.

A experiência chilena dos últimos 20 anos, utilizada como referência para a criação de programas habitacionais de combate ao déficit habitacional, especialmente pelo Banco Mundial, ${ }^{15}$ mostra que uma política massiva de financiamento e subsídio habitacional acabou criando um novo problema habitacional e urbano, com um enorme estoque de habitação social inadequado que se transformou em um passivo incômodo para os agentes financeiros e para os moradores. Hoje o Chile vive o dilema do que fazer com os seus "com teto". As centenas de milhares de casas e apartamentos da supostamente exitosa política habitacional chilena produziram um território marcado por uma segregação profunda, onde o lugar dos pobres é uma periferia homogênea, de péssima qualidade urbanística e, muitas vezes, também, de péssima qualidade de construção, marcada ainda por sérios problemas sociais, como tráfico de drogas, violência doméstica, entre outros (Rodriguez e Sugranyes, 2005).

Apesar dos muitos bilhões de reais em subsídios públicos, o PMCMV não impacta a segregação urbana existente, apenas a reforça, produzindo novas manchas urbanas monofuncionais ou aumentando a densidade populacional de zonas guetificadas já existentes. Assim como no caso da política habitacional chilena, cujo modelo foi usado como fonte de inspiração, a experiência do PMCMV evidencia a dificuldade de se conciliar uma política pública guiada por uma racionalidade de mercado com o desafio de produzir cidade para todos, o que não se alcança por meio de uma lógica de inclusão pelo consumo, dependendo de uma perspectiva de universalização de direitos. 


\section{Raquel Rolnik}

Universidade de São Paulo, Faculdade de Arquitetura e Urbanismo, Departamento de Projeto, Coordenadora do Laboratório Espaço Público e Direito à Cidade. São Paulo/SP, Brasil

raquelrolnik@gmail.com

\section{Alvaro Luis dos Santos Pereira}

Universidade de São Paulo, Faculdade de Direito, Laboratório Espaço Público e Direito à Cidade. São Paulo/SP, Brasil.

alvarolsp@yahoo.com

\section{Fernanda Accioly Moreira}

Universidade de São Paulo, Faculdade de Arquitetura e Urbanismo, Laboratório Espaço Público e Direito à Cidade. São Paulo/SP, Brasil.

fefaccioly@gmail.com

\section{Luciana de Oliveira Royer}

Universidade de São Paulo, Faculdade de Arquitetura e Urbanismo, Departamento de Projeto, Laboratório Espaço Público e Direito à Cidade. São Paulo/SP, Brasil.

luroyer@gmail.com

\section{Rodrigo Faria Gonçalves lacovini}

Universidade de São Paulo, Faculdade de Arquitetura e Urbanismo, Laboratório Espaço Público e Direito à Cidade. São Paulo/SP, Brasil.

rfgiaco@yahoo.com.br

\section{Vitor Coelho Nisida}

Universidade de São Paulo, Faculdade de Arquitetura e Urbanismo, Laboratório Espaço Público e Direito à Cidade. São Paulo/SP, Brasil.

coelhonisida@gmail.com

\section{Colaboradores}

\section{Ana Paula de Oliveira Lopes}

Universidade de São Paulo, Faculdade de Arquitetura e Urbanismo, Laboratório Espaço Público e Direito à Cidade. São Paulo/SP, Brasil.

ana.paula.2592@gmail.com

\section{Luis Guilherme Alves Rossi}

Universidade de São Paulo, Faculdade de Arquitetura e Urbanismo, Laboratório Espaço Público e Direito à Cidade. São Paulo/SP, Brasil.

lu.garossi@gmail.com 


\section{Notas}

(1) A Rede Cidade e Moradia constituiu-se a partir da Chamada Pública MCTI/CNPq/MCIDADES n. 11/2012, uma iniciativa promovida pelo Governo Federal para avaliar os resultados do PMCMV. Fazem parte da rede as seguintes instituições: LabCidade - FAU/USP; Instituto Pólis; Peabiru; PUC/SP; FAU-São Carlos; IPPUR/UFRJ; FAU/UFRJ; UFMG; UFRN; UFC; UFPA. Com base num método de análise desenvolvido coletivamente, as instituições mencionadas conduziram pesquisas sobre o padrão de inserção urbana dos empreendimentos do PMCMV em diversas cidades do país, discutindo regularmente as constatações feitas a partir dos respectivos objetos de estudo.

(2) Foi feito o mapeamento dos empreendimentos do PMCMV das regiões metropolitanas de São Paulo e de Campinas contratados pela Caixa Econômica Federal (Caixa) entre março de 2009 (início do programa) e 31 de dezembro de 2012. O levantamento foi feito a partir de uma base de dados elaborada pela Caixa e fornecida pelo Ministério das Cidades, o que ensejou o referido recorte temporal. Os empreendimentos integrantes da planilha de dados fornecida foram localizados a partir de imagens de satélite e georreferenciados pela equipe do LabCidade. Cabe ressalvar que, em virtude de fatores como a imprecisão dos endereços fornecidos e a desatualização de algumas imagens, não foi possível localizar todos os empreendimentos contratados no período mencionado, de modo que aproximadamente $10 \%$ não foram localizados. Acredita-se que, por tratar-se de uma parcela pequena da amostra analisada, a ausência desses empreendimentos nas representações cartográficas divulgadas nesse artigo não prejudicou as interpretações realizadas.

(3) O debate sobre a segregação socioespacial é um tema que ensejou extensa produção bibliográfica no campo dos estudos urbanos. Há um amplo debate na literatura estrangeira a respeito da segregação em função de fatores étnico-raciais (Wacquant, 2008). Mais recentemente, alguns estudos passaram a refletir sobre a chamada segregação voluntária de grupos de alto poder aquisitivo em edifícios murados e condomínios horizontais afastados das cidades (Caldeira, 2000). Fugiria aos objetivos deste artigo aprofundar-se neste debate teórico e abordar de modo sistemático os diversos sentidos associados ao termo "segregação". Estamos empregando este conceito numa acepção específica, utilizando-o para denotar uma separação física entre grupos socias no espaço urbano em função da renda, com a concentração de grupos de menor poder aquisitivo em periferias distantes e deficientes em infraestrutura, equipamentos e serviços públicos, pouca oferta de emprego e baixa diversidade de usos.

(4) O programa foi inicialmente instituído pela MP 459, de 25/3/2009, substituída pela Lei 11.977 , de 7/7/2009, e regulamentado pelos Decretos 6819, de 13/4/2009 e 6962, de 19/9/2009.

(5) No início do programa, as faixas eram definidas em função do salário mínimo, de modo que a Faixa 1 destinava-se ao atendimento de famílias com renda mensal entre 0 e 3 s.m., a Faixa 2 entre 3 e 6 s.m., e a Faixa 3 entre 6 e 10 s.m. A partir de 2011, passou-se a definir as faixas com base em valores nominais.

(6) Nos empreendimentos contratados na primeira fase, o valor das prestaçãos correspondia a $10 \%$ da renda familiar mensal, com prestação mínima de $\mathrm{R} \$ 50,00$. A partir da segunda fase, a prestação mensal foi reduzida para $5 \%$ da renda familiar mensal, com limite mínimo de $\mathrm{R} \$ 25,00$. 
(7) Esses valores estão definidos no Anexo I da Portaria MCidades $n^{\circ}$ 168, de 12 de abril de 2013. Podem oscilar entre um valor unitário máximo de $\mathrm{R} \$ 54.000,00$ nos empreendimentos do tipo casa, produzidos em municípios com população inferior a 50 mil habitantes nos estados de $A L$, MA, PB, RN, SE e PI; e um valor unitário máximo de $\mathbf{R} \$ 76.000,00$ para casas ou apartamentos produzidos em Brasília, em municípios integrantes das regiões metropolitanas de São Paulo, Campinas e Baixada Santista e no município de Jundiaí. Esses limites dizem respeito aos valores financiáveis pelo FAR, podendo vir a ser elevados por meio de contrapartidas oferecidas por estados e municípios.

(8) O FAR também pode custear ações complementares à implantação do empreendimento, como a construção de equipamentos públicos em suas imediações, a extensão de redes de saneamento básico e ações voltadas à capacitação dos moradores para a gestão condominial. Essas ações não integram o objeto do contrato entre o FAR e a construtora numa operação, nem o cálculo do valor das unidades - embora o cálculo dos recursos disponíveis para a construção de equipamentos e a capacitação para a gestão condominial estejam atrelados ao valor da operação a que estão associados.

(9) Em entrevista com representantes de uma das construtoras de grande porte que atuam no programa, foi afirmado que, com taxas de retorno inferiores a 15\%, só vale a pena construir empreendimentos de Faixa 1 acima de 600 U.H.

(10) Em entrevista com representantes do setor construtivo, afirmou-se que o valor pago por metro quadrado em regiões metropolitanas pode variar entre $\mathrm{R} \$ 50$ e $\mathrm{R} \$ 200$ reais, sendo inviável a realização de empreendimentos para a Faixa 1 em terrenos que extrapolem esses limites. Afirmou-se ainda que os terrenos que têm sido destinados para a Faixa 1 em regiões metropolitanas são aqueles que sequer participariam do mercado de terra, caracterizando-se como glebas que, sem a existência de subsídio público para a produção de moradias populares, simplesmente não entrariam no circuito de produção imobiliária.

(11) Essas exigências foram sendo progressivamente ampliadas e submetidas a procedimentos de avaliação mais criteriosos ao longo da evolução do programa. A aprovação da maior parte das operações contratadas no período abrangido por esta pesquisa, entretanto, não foi submetida aos procedimentos de avaliação exigidos pelas normativas mais recentes. É possível que essas exigências interfiram de alguma forma no padrão de localização dos empreendimentos. No entanto, é preciso que transcorra mais tempo de aplicação das novas regras para que seus impactos possam ser avaliados.

(12) Além da categoria "Contiguidade" adotada nesta pesquisa, julgamos necessário ainda observar outro fenômeno urbano semelhante, que denominamos "Agrupamento". Para isso, foi definido um raio de abrangência para cada empreendimento georreferenciado e foram identificados os casos em que esse raio intercepta as zonas de abrangência de outros empreendimentos. Com isso buscamos ilustrar casos também muito comuns de bairros e regiões em que ocorre uma grande concentração de empreendimentos do programa, de mesma construtora ou não, revelando a formação de regiões com grande potencial de gerar áreas de monofuncionalidade e homogeneidade social.

(13) As considerações feitas em relação aos padrões de uso e ocupação do solo dizem respeito aos usos formais. Apesar da predominância de usos exclusivamente residenciais, foram identificados diversos exemplos de usos informais relacionados a comércio e serviços nas áreas estudadas, o que evidencia o irrealismo das formas de ocupação do solo de caráter monofuncional. 
(14) O IPVS é um indicador resultante da combinação entre das dimensões socioeconômica e demográfica, que classifica cada setor censitário (território contínuo dentro do município que possui em média 300 domicílios) em grupos de vulnerabilidade social, desenvolvido pela Fundação Seade.

(15) WORLD BANK. Housing: Enabling housing markets to work. Washington: WB, 1993, e WORLD BANK. Cities in transition: Urban and local government strategy. Washington: WB, 2000.

\section{Referências}

ARANTES, P. e FIX, M. (2009). 'Minha Casa Minha Vida', o pacote habitacional de Lula. Disponível em: http://www.correiocidadania.com.br/content/blogcategory/66/171/.

BARONE, M. (2009). "Pobreza e mobilidade: como os pobres se locomovem no espaço metropolitano". In: BÓGUS, L. M. M. e PASTERNAK, S. (orgs.). Como anda São Paulo. Rio de Janeiro, Letra Capital/ Observatório das Metrópoles.

BÓGUS, L. M. M. e PASTERNAK, S. (orgs.) (2009). Como anda São Paulo. Rio de Janeiro, Letra Capital/ Observatório das Metrópoles.

BONDUKI, N. (2009). Do Projeto Moradia ao Programa Minha Casa Minha Vida. Teoria e Debate, n. 82. São Paulo, Editora Perseu Abramo.

BONDUKI, N. e ROLNIK, R. (1979). “Periferia da Grande São Paulo: reprodução do espaço como expediente de reprodução da força de trabalho". In: MARICATO, E. (org.). A produção capitalista da casa (e da cidade) no Brasil industrial. São Paulo, Alfa-Ômega.

BRIGGS, X. de S. (org.). (2005). The geography of opportunity: race and housing choice in Metropolitan America. Washington, The Brookings Institution.

CAIADO, M. C. S. e PIRES, M. da C. S. (2006). “Campinas Metropolitana: transformações na estrutura urbana atual e desafios futuros". In: CUNHA, J. M. P. da (org.). Novas metrópoles paulistas: população, vulnerabilidade e segregação. Campinas, Nepo/Unicamp.

CALDEIRA, T. P. do R. (2000). Cidade de muros: crime, segregação e cidadania em São Paulo. São Paulo, Editora 34/Edusp.

COMIN, A. (2011). "Cidades-regiões ou hiperconcentração do desenvolvimento? O debate visto do Sul”. In: KOWARICK, L. e MARQUES, E. (orgs.). São Paulo: novos percursos e atores (sociedade, cultura e política). São Paulo, Ed. 34/CEM.

KOWARICK, L. e MARQUES, E. (orgs.). (2011). São Paulo: novos percursos e atores (sociedade, cultura e política). São Paulo, Ed. 34/CEM.

KRAUSE, C.; BALBIM, R. e LIMA NETO, V. C. (2013). Minha Casa Minha Vida, Nosso Crescimento: onde fica a Política Habitacional? Texto para discussão 1853. Rio de Janeiro, IPEA, agosto. 
MARICATO, E. (1996). Metrópole na periferia do capitalismo: ilegalidade, desigualdade e violência. São Paulo, Hucitec.

(2009). O "Minha Casa" é um avanço, mas segregação urbana fica intocada. Carta Capital, 27 maio.

MARQUES, E. e TORRES, H. (orgs.). (2005). São Paulo: segregação, pobreza e desigualdades sociais. São Paulo, Senac São Paulo.

MARQUES, E. e REQUENA, C. (2013). O centro voltou a crescer? Trajetórias demográficas diversas e heterogeneidade na São Paulo dos anos 2000. Novos Estudos Cebrap, v. 95, pp. 17-36.

MOYA, M. E. (2011). “Os estudos sobre a cidade: quarenta anos de mudança nos olhares sobre a cidade e o social". In: KOWARICK, L. e MARQUES, E. (orgs.). São Paulo: novos percursos e atores (sociedade, cultura e política). São Paulo, Ed. 34/CEM.

PASTERNAK, S. (2009). “Aspectos demográficos da Região Metropolitana de São Paulo”. In: BÓGUS, L. M. M. e PASTERNAK, S. (orgs.) (2009). Como anda São Paulo. Rio de Janeiro, Letra Capital/ Observatório das Metrópoles.

RODRIGUEZ, A. e SUGRANYES, A. (orgs.). (2005). Los con Techo: un desafío para la política de vivienda social. Santiago, Ediciones SUR.

ROLNIK, R. e FRÚGOLI, H. (2001). Reestruturação urbana da metrópole paulistana: a Zona Leste como território de rupturas e permanências. Cadernos Metrópole. São Paulo, n. 6, pp. 55-83.

TASCHNER, S. P. (2001). Desenhando os espaços da pobreza. Tese de Livre-Docência. São Paulo, Universidade de São Paulo.

TORRES, H. G. (2005). “Medindo a segregação”. In: MARQUES, E. C. e TORRES, H. G. (orgs.). São Paulo: segregação, pobreza e desigualdades sociais. São Paulo, Editora do Senac.

VILLAÇA, F. (1998). Espaço intraurbano no Brasil. São Paulo, Nobel/Fapesp.

WACQUANT, L. (2008). As duas faces do Gueto. São Paulo, Boitempo.

Texto recebido em 18/mar/2014

Texto aprovado em 14/out/2014 